https://helda.helsinki.fi

\title{
An exploration of longitudinal studies of digital learning
}

\author{
Harju, Vilhelmiina
}

2019-10-02

Harju , V , Koskinen , A \& Pehkonen , L 2019 , ' An exploration of longitudinal studies of digital learning ' , Educational Research , vol. 61 , no. 4 , pp. 388-407 . https://doi.org/10.1080/00131881.2019.16605

http://hdl.handle.net/10138/327206

https://doi.org/10.1080/00131881.2019.1660586

acceptedVersion

Downloaded from Helda, University of Helsinki institutional repository.

This is an electronic reprint of the original article.

This reprint may differ from the original in pagination and typographic detail.

Please cite the original version. 


\section{An exploration of longitudinal studies of digital learning}

Vilhelmiina Harju $^{\mathrm{a} *}$, Antti Koskinen ${ }^{\mathrm{b}}$, and Leila Pehkonen ${ }^{\mathrm{a}}$

${ }^{a}$ Faculty of Educational Sciences, University of Helsinki, Finland; ${ }^{b}$ TUT Game Lab, Tampere University of Technology, Pori, Finland

*Corresponding author: Vilhelmiina Harju, Faculty of Educational Sciences, University of Helsinki, P.O. Box 9, 00014 University of Helsinki, Finland, +358407047971, vilhelmiina.harju@ helsinki.fi, ORCID: 0000-0001-6585-5382

Antti Koskinen Tampere University of Technology, Pori, PO Box 300, FI-28101 Pori, Finland, antti.koskinen@tut.fi, ORCID: 0000-0002-9755-1057

Leila Pehkonen Faculty of Educational Sciences, University of Helsinki, P.O. Box 9, 00014 University of Helsinki, Finland, leila.pehkonen@ @elsinki.fi, ORCID: 0000-0001-7695-6939

\section{Biographical notes}

Vilhelmiina Harju M.A. (Ed), is a doctoral student at the Faculty of Educational Sciences, University of Helsinki. Her main research interests are lifelong learning, teachers' professional development, non-formal learning environments, and learning and teaching with digital technologies.

Antti Koskinen is doctoral student at Tampere University of Technology. His main research interests are game-based learning, rational number learning and digital learning environments.

Leila Pehkonen $\mathrm{PhD}$, adjunct professor is working at the Faculty of Educational Sciences, University of Helsinki. Her research interests include teaching and learning at various levels of education

\section{Acknowledgments}

The authors wish to thank the Ministry of Education and Culture in Finland for funding the TOTEEMI project, of which this study is part.

\section{Funding}

This work was supported by the Ministry of Education and Culture in Finland under Grant OKM/172/523/2016.

\section{Declaration of interest statement}

No potential conflict of interests. 


\section{Structured abstract}

Background: The importance of digital technologies for enhancing learning in formal education settings has been widely acknowledged. In light of this expectation, it is important to investigate the effects of these technologies on students' learning and development.

Purpose: This study explores longitudinal empirical research on digital learning in the context of primary and secondary education. By focusing on a small selection of the peer-reviewed literature, the aim is to examine the kinds of longitudinal study published on this topic during the period 2012-2017 and, thorough categorization, to bring together insights about the reported influences of digital technology use on students' learning.

Design and methods: The databases searched for the purposes of this review were Scopus and Web of Science. Of 1,989 articles, 13 were finally included in the review. Using qualitative content analysis, these were analysed, coded and categorised.

Results: The reviewed studies were found to have approached digital learning in different ways: they varied, for example, in terms of research methods and design and the digital technologies used. The studies addressed different aspects of learning, which we assigned to six categories: affection, attitude, and motivation; subject-specific knowledge and skills; transversal skills; learning experience; elements of the learning environment; and identity. We identified both positive and negative influences of technology on learning.

Conclusions: This review offers a snapshot of the variety of research in this fast-moving area. The studies we explored were found to approach digital learning from several different perspectives, and no straightforward conclusions can be drawn about the influences of digital technology use on students' learning. We conclude that further longitudinal studies of digital learning are needed, and the present study assists by highlighting gaps in the existing literature.

Keywords: digital learning, digital technology use, literature review, longitudinal research, primary and secondary education

\section{Introduction}

During the past few decades, digital technologies have strengthened their position as a salient driver of learning (Higgins, Xiao, and Katsipataki 2012; Kozma 2010). Digital learning, learning facilitated and supported by digital technologies, is seen as an essential part of formal education, and countries around the world have integrated use of digital technologies into their 
national curricula. This development is, of course, part of a larger societal move toward digitalisation (e.g. Nagy and Koles 2014; Tilson, Lyytinen, and Sørensen 2010). Two major questions facing the field of education are: how can digital technology usage actually enhance and strengthen individuals' learning and development? and, what are the long-term effects of technology use on students' learning?

As expectations of the potential benefits of digital technologies remain high, it is important to investigate the influences these technologies have on students' learning (e.g. Olofsson et al. 2011). Sometimes, studies focusing on these themes are empirical case studies or experiments of relatively short duration that may not take the specific learning context into account. This has led several researchers to call for longitudinal research about the topic (Olofsson et al. 2011; Mikropoulos and Natsis 2011; Tay 2016). According to Menard (1991), longitudinal research has the potential to describe patterns of change and establish the direction and magnitude of causal relationships. By exploring and categorising, in detail, a small selection of longitudinal studies of digital learning, this study aims to bring together insights about the reported influences of digital technology on student learning.

\section{Digital technologies in education}

Different educational stakeholders have described the importance of digital technologies in formal education (Olofsson et al. 2011). The arguments for integrating digital technologies into education are familiar: ability and skill in using the rapidly-evolving digital technologies is widely regarded as a key competence needed for modern life. Several organisations and research groups around the world have outlined frameworks for what are often referred to as ' $21^{\text {st }}$ century skills', or transversal skills, in which digital competence plays a central role (e.g. Ananiadou and Claro 2009; Binkley et al. 2012; European Commission 2018a; European 
Commission 2018b). As observed by the European Commission (2018a, 3), '[t]he rapid digital transformation of the economy means that almost all jobs now require some level of digital skills, as does participation in society at large. Digital skills are now as vital as literacy and numeracy and Europe therefore needs digitally competent people who are not only able to use but also to innovate and lead in using these technologies'. Education can be seen as a central component in enhancing these competences for citizens (e.g. Groff 2013).

Digital technologies, it is argued, can bring wide ranging benefits to education. For example, it is often held that digital technologies have the potential to diversify and enrich teaching in schools. As tools for instruction, it is suggested that they can decrease barriers to education by improving accessibility and reducing costs (Geith and Vignare 2008; Yuan and Powell 2013). Digital technologies can also change the teaching methods used (Pyyry et al. 2017) and can influence how students' development is assessed and tracked (Rautopuro and Harjunen 2017). They can also influence methods of cooperation and collaboration with members inside and outside school (Blau and Shamir-Inbal 2017). In addition, digital technology usage is viewed as having important effects on students' learning processes. Several studies describe digital technologies as essential promoters, supporters, and enablers of learning (e.g. Kozma 2010). Through integration of digital technologies into teaching in a pedagogically meaningful way, students can better engage in learning processes and achieve objectives set in curricula.

\section{Conceptualisation of learning and digital learning}

The complex notion of learning and what it means to learn has been conceptualised in a variety of different ways. Hergenhahn and Olson $(2005,8)$ define learning as 'a relatively permanent change in behaviour or in behavioural potentiality that results from experience'. According to them, depending on the learning theory or paradigm espoused by a researcher, the experience 
necessary for learning can include reinforced practice, contiguity between a stimulus and a response, or the acquisition of information. Several definitions of learning also emphasise its functional and productive origin (e.g. De Houwer, Barnes-Holmes, and Moors 2013). For example, Lonka et al. (2015) states that human cognition is always embedded in a certain historical time, within its culture and its tools, and cannot thus be restricted to mental models. According to Lonka et al. $(2015,16)$, '[1] earning is an interactive process of participating in cultural practices and shared activities that structure and shape cognitive activity in many ways'. Sociocultural approaches emphasise the notion that individuals' cognitive abilities, such as thought and memory, develop in interactive processes with an environment; only after practising new abilities in social situations can these be internalised and exercised individually (Stahl 2013; Vygotsky 1978). When learning is defined as a productive process or as active participation, it comes very close to the process of studying (e.g. Dunlosky et al. 2013): that is, goal-oriented acquisition of knowledge and competence. Emotions, engagement, attitudes, and personal experiences are viewed as essential and influential parts of the learning process (e.g. Eshghinejad 2016; Ketonen et al. 2016; Tyng et al. 2017).

In this study, we use the term 'digital learning' to refer to students using digital technology as a part of instruction in a formal educational context. Here, we do not limit our view of learning to a certain viewpoint but, rather, aim to explore the variety of ways in which recent studies have approached digital learning and investigated the indications of students' learning. We use the term 'digital technology' to refer a wide variety of content. It can include digital learning materials, such as e-books; certain activities or teaching methods, such as serious games and digital storytelling; and certain devices, software, or programs that aim to support studying, learning, and instruction. 
Research on digital learning has tended to focus on its influences on students' learning processes. Several literature reviews about the topic have provided helpful and informative descriptions of work carried out in this area. For example, in their literature review about technology usage in mathematics education research, Bray and Tangney (2017) categorised the aims set for certain digital technologies that were used to support learning in educational context. These aims were attributed to different aspects of the learning process - for example, change in attitude (e.g. student motivation, self-efficacy, and engagement); improved performance; development of conceptual understanding; and generation of metacognitive skills (e.g. collaboration, problem-solving, and creative skills). Elsewhere, in a review of experimental and survey-based research about information and communication technology (ICT) usage in school settings, Pérez-Sanagustín et al. (2017) identified both quantitative, qualitative, and mixed-methods studies. This study categorised the reviewed papers according to the duration of the intervention period. From the reviewed articles, it is evident that $21 \%$ included long-term interventions (referring to more than 12-week-long periods or 12 sessions), $14 \%$ were middle-term interventions (5-12 weeks or sessions), and $9 \%$ were short-term interventions (fewer than five weeks or sessions). The number of long-term interventions seems quite high in comparison with the percentages with middle- and short-term interventions. However, it is important to note that of the total number of reviewed papers $(\mathrm{N}=352), 56 \%$ were classified as 'not applicable/no information'. This category included studies based on one single intervention or existing data that did not require further data collection. In addition, it included studies in which information of the length of the intervention or number of sessions was not mentioned. This suggests that it is quite difficult to establish, with certainty, the proportion and nature of studies that may be classified as long-term interventions. 
Aims

There is a need to investigate what kind of longitudinal research has already been carried out in order to explore and better understand the influences of digital technology use on students' learning. By focusing on a small, specific collection of current longitudinal studies of digital learning in primary and secondary education, this study aims to provide an updated snapshot of this important area of research by addressing the following questions:

1. What kinds of longitudinal study have been published on the topic during the period 2012-2017?

2. What influences of digital technology usage on student learning did these studies report?

\section{Methods of data collection and analysis}

\section{Databases and search terms}

The databases searched for the purposes of this review were Scopus and Web of Science. In Scopus, we used title, abstract, and keywords search depth; in Web of Science, we used topic search depth. As our primary focus was to explore the topic at a general level and concentrate on peer review journal articles, we decided to use these two major electronic databases, which have previously been used (e.g. Chadegani et al. 2013) to search the relevant literature in this

area. The search terms were chosen by the research group. Before deciding on terms used, several preliminary searches with different search terms were concluded to achieve a broad scope of the field. Several search terms were rejected at this initial stage, as they limited the results too much or did not result in papers relevant to the research aims. 
The term 'longitudinal' was included in all of the search strings, in order to focus on studies that had been described in this way by their authors. Menard $(1991,4)$ defined longitudinal research as 'research in which (a) data are collected for each item or variable for two or more distinct time periods; (b) the subjects or cases analysed are the same or at least comparable from one period to the next; and (c) the analysis involves some comparison of data between or among periods'. According to Menard, data gathering approaches and methods vary, as do periods for which data are collected - from a matter of hours to several years. As our aim was to explore the range of longitudinal research conducted on the topic, we adopted Menard's definition and focused on studies that described patterns of change in some form. No requirements were set in terms of data collection methods or length of the study. This decision acknowledged that the term 'longitudinal' has different meanings in research contexts, and that the reviewed studies were likely to differ (perhaps greatly) in terms of their chosen study period. The term 'longitudinal' was combined with 'technology' or 'digital', as we wanted to narrow the search to include only articles discussing the use of digital technology. On the other hand, these keywords were broad enough not to limit the search to certain teaching methods, digital devices, or applications. Finally, the keywords mentioned above were combined with one of these terms: 'education', 'school', 'teaching', or 'learning'. These terms were chosen to narrow the search to a formal educational context.

\section{Inclusion and exclusion criteria}

To maintain focus on the research goal, certain inclusion and exclusion criteria were used to inform the search for relevant papers. These criteria were applied when identifying papers based on title, abstract, and keywords, as well as when evaluating suitability based on full-text reading. Specifically, we included papers relevant to the research aims of the study that were: published in peer-reviewed journals; included empirical evidence about students' learning; 
were written in English; used some of the phrases: longitudinal study, longitudinal research, longitudinal research project, longitudinal design, or longitudinal effects to describe the research; described patterns of change; were published between the years 2012-2017; included participants primarily in primary or secondary education and could be accessed from University of Helsinki. We excluded from the review papers that primarily used technology in non-formal learning environments or laboratories; focused primarily on students with special needs and papers that focused on investigating certain parts of longitudinal data instead of examining patterns of change.

\section{Paper identification and selection process}

Figure 1 shows that the database search produced 1,989 papers. Based on an analysis of the titles, abstracts, and keywords, 171 relevant papers were included in further analysis. After removing the duplicates $(\mathrm{N}=100)$ and papers for which we did not have full text access $(\mathrm{N}=7)$,

64 papers remained. Based on full-text reading of the 64 publications, a small collection of 13 papers were included in the final analysis, as they met the predefined criteria. The grounds for excluding the remaining 51 included the following: the studies were not focused on primary or secondary education $(\mathrm{N}=13)$; the authors did not define their study as longitudinal, or the study did not describe patterns of change $(\mathrm{N}=13)$; the study did not focus on students' learning $(\mathrm{N}$ $=17)$; or the study was not conducted in formal school settings $(\mathrm{N}=7)$. In addition, one study included no empirical evidence regarding students' learning.

[Figure 1 near here] 


\section{Data coding and analysis}

The final selection of 13 papers were coded in order to extract and analyse the information. A coding table was constructed, comprising two sections defined by the research aims. The first section was designed to capture the studies' general description and contained information about such matters as the digital technology used and the school subject it was integrated with, as well as participants, methods, and study duration. This information was further classified and categorised inductively, according to the content. The second section captured the reported influences of digital technology usage on student learning. As the selected studies approached digital learning from different viewpoints, categories were created to reflect the different aspects of learning on which the studies focused. These categories were based on qualitative content analysis, and their descriptions were created through a reciprocal interaction between the studies' content, different perspectives on learning (e.g. Dunlosky et al. 2013; Hergenhahn and Olson 2005; Lonka et al. 2015), and previous research (e.g. Bray and Tangney 2017). The six categories and their descriptions were:

1. Affection, attitude, and motivation

Motivation and willingness to do a certain activity. Engagement in the learning process and the ways a technology is used (e.g. is use in accordance with the pedagogical aims?). Feeling or attitude towards a certain object or activity.

2. Subject-specific knowledge and skills

Knowledge acquisition or content understanding; learning of skills related to a certain discipline or subject. 


\section{Transversal skills}

Competences and skills that are not limited to one academic discipline or knowledge area but are essential in learning and working in a wide variety of situations (UNESCO International Bureau of Education 2013). In this category of study, these skills include critical thinking, knowledge creation, communication, and digital skills.

\section{Learning experience}

Experience of, or beliefs about, one's own learning. Learning perceived as studying.

5. Elements of the learning environment

Material and social resources of a learning environment.

6. Identity

Construction of identity by using digital technology.

It is important to note that most of the reviewed articles were coded into more than one of these categories, as they approached students' learning from several aspects.

In order to answer the second research question: i.e. what influences of digital technology usage on students' learning did the reviewed studies report, an interpretation of the reported outcomes was undertaken. Again, the outcomes were approached inductively, and they were coded to relate to one or more of the categories specified above. 


\section{Results}

\section{Descriptions of the longitudinal studies included in the analysis}

The summarised description of the reviewed articles is shown in Table 1. Further descriptions of the different features are presented in the paragraphs below.

[Table 1 near here]

Research design: From the 13 articles that were analysed, six were categorised as case studies. This category included studies describing a special initiative, project, or programme from several perspectives or with diverse data collection methods. Three of these studies were defined as longitudinal case studies by the authors themselves, whereas two were placed in this category according to the purposes of the study and the methodological choices made. Five of the reviewed articles were classified in the 'experimental or quasi-experimental design' category. These studies commonly focused on implementing pre- and post-test-measures and aimed to measure the impact of the introduction of certain technology on students' studying and learning. Finally, two of the studies that we reviewed were classified in the descriptive design' category. This category differed from the first category in that it included studies that principally utilised one data collection method and explored particular themes related to a technology introduction process: digital competence and its transformation of everyday school and classroom practices, discussions on an online learning platform, or student acceptance of digital devices.

Data collection methods: In all, four of the reviewed articles combined both qualitative and quantitative data collection methods, six were quantitative, and three qualitative. 
Duration of studies: Because of the multiple methods and study designs used in the reviewed studies, information about duration of studies could not be coded univocally. It was sometimes problematic to identify how often digital technologies were used, how often the data were collected, and the duration of a data collection period. For example, in some studies, data were collected in regular intervals (e.g. Semeraro et al. 2017), whereas others did not specify the number of times the data were gathered from participants (Adhikari et al. 2017). In addition, the duration of data collection could vary within a study. For example, Wales (2012) described how a digital storytelling method was used with three young people. Two of the described cases were about 10 months in duration, whereas another lasted three and a half years. Due to these variations, we focused on the time periods mentioned in the reviewed articles during which the study projects were conducted. The durations varied from five months to eight years. However, it is worth mentioning that the duration of a project did not, in every case, directly correspond to the duration of a data collection period. For example, $\mathrm{Ng}$ and Nicholas (2013) reported results of a longitudinal study that lasted about three years. However, the results discussed in the study are based mainly on the data gathered after one year. Table 1 presents more detailed information about the duration of studies.

Participants: In seven of the studies, participants were students. In five studies, participants sometimes also included teachers, parents, a principal, or other project partners, such as graduate students or a programme coordinator. In one study, participants included only teachers. The number of participants also varied: in three studies, the number was 25 or fewer, and in another three, the number of participants was 40-84. In six studies, more than 200 participants were involved. The study of Harnisch, Comstock, and Bruce (2014) did not mention the exact number of participants, but several school classrooms across a state 
participated in the study. In addition, as several studies included more than one phase of data collection, the number of participants could vary during the project. In Table 1, which summarises the descriptions of the articles that were reviewed, the number of participants is presented as the highest reported number from the data collection periods. This figure may not include the number of people who were, along with other data collection methods, observed during the study.

Digital technologies used: The studies were categorised based on the general research focus of technology use. Five of the reviewed studies focused on changes that the overall use of technology had on students' learning. In these studies, students used personal laptops or other types of personal computing devices for studying and learning (Adhikari, Mathrani, and Scogings 2016; Adhikari et al. 2017; Bate, MacNish, and Males 2012; Courtois et al. 2014; Ng and Nicholas 2013). Six studies focused on investigating the use of certain computer programs or software. Harnisch, Comstock, and Bruce (2014) investigated the use of computer-based modelling, scientific visualisation, and informatics tools in science and mathematics education, whereas Alvarez-Marinelli et al. (2016) investigated the use of two English-language-learning programs in teaching. In the study by Ale, Loh, and Chib (2017), students used laptops with five pre-installed programs related to mathematics and language learning. Baker, Bernard, and Dumez-Féroc (2012) examined how a communication and collaborative work programme was used in the classroom for debates and argumentation. Bicer and Capraro (2017) presented a study in which students were provided with handheld devices during maths classes. These devices included advanced graphing calculators with multiple mathematical features. Semeraro et al. (2017) investigated how a serious game improved students' cardiopulmonary resuscitation (CPR) skills. In addition to these categories, digital technologies examined in the articles we reviewed included digital storytelling as a method for development and learning (Wales 2012) 
and a learning platform aimed at English-language-learning that included different learning materials, discussion groups, a wiki, and a private YouTube space (Liontou 2015).

School subjects: The subjects in which a certain digital technology was integrated included mathematics, English language, Hindi language, and history-geography. In six studies, the use of digital technology was integrated in several subjects or disciplines. In a further two studies, a serious game was used to teach students CPR skills (Semeraro et al. 2017) and digital storytelling was used to support students in constructing identities for and through their digital stories (Wales 2012).

Educational context: As countries differ in their educational systems, and the terminology used is not congruent globally, we categorised the studies in two categories indicating educational context: primary and secondary school. The category of primary school included studies carried out in primary, elementary, or junior school settings and the category of secondary school contained studies that were reported to be carried out in secondary, middle, or high schools, or junior high school settings.

Locations: The locations in which the studies were carried out were: Australia, Belgium (Flanders), Costa Rica, France, Greece, India, Italy, New Zealand, Singapore, and the United States of America.

\section{Reported influences of digital technology use on students' learning}

The second aim of the study was to explore the reported influences of digital technology use on students' learning. We approached this aim by creating categories regarding the aspects of learning on which the studies focused. In all, six categories were created: Affection, attitude, 
and motivation $(\mathrm{N}=8)$, Subject-specific knowledge and skills $(\mathrm{N}=5)$, Transversal skills $(\mathrm{N}=6)$, Learning experience $(\mathrm{N}=4)$, Elements of the learning environment $(\mathrm{N}=3)$, and Identity $(\mathrm{N}=1)$. Next, the second research question is addressed by presenting the results according to these six categories.

Affection, attitude, and motivation: The category of 'Affection, attitude, and motivation' aggregated results related to feelings, willingness, and attitudes to a certain object or activity. It also included results related to students' engagement in the learning process or motivation to participate in certain learning activities. The articles we reviewed found both positive and negative indications of students' affection, attitude, and motivation in relation to digital learning. For example, Adhikari, Mathrani, and Scogings (2016) found that a majority of students experienced digital devices and their effects on teaching and learning positively. They also found a small increase in students' device usage for educational purposes. This, according to the authors, demonstrates a positive trend in student motivation for digital learning. Adhikari et al. (2017), in turn, approached students' motivation from the teacher's viewpoint. Their analysis revealed mainly positive outcomes in relation to motivation, although some students were described as not engaged or motivated to use digital devices for learning. In a study of attitudes and general perceptions in relation to online teaching practices among students learning English as a foreign language, Liontou (2015) reported positive perceptions that ranged from fair to very satisfactory. Just a small percentage of students found the online course only slightly interesting to follow. These positive perceptions may, in part, reflect students' preexisting attitudes, as reported by Courtois et al. (2014), who found that students' a priori attitudes towards tablet devices persisted, even months after they were first measured. 
Engagement and motivation can also stem from freedom experienced in the learning situation. Wales (2012) examined digital storytelling in both formal and informal learning contexts and reported that participants in informal learning environments first tried to create stories that they believed their teachers would like them to tell. Once they realised there were no expectations, their engagement level rose, and they also began to mentor other young people who had just joined the digital storytelling project. According to Wales $(2012,549)$, the findings 'reveal an interrelationship between agency, engagement, confidence, skill-set, and the ability to communicate a story'.

However, freedom of activity did not always lead to the desired educational goals. Despite several positive reported indications, Adhikari, Mathrani, and Scogings (2016) also noted that when a digital initiative was introduced, about 50 per cent of students reported using digital devices mainly for non-educational activities such as social media and games. In addition, 17 per cent of teachers reported that it was a challenge to keep students on task with the devices. Similar findings were reported by Bate, MacNish, and Males (2012), who noted that off-task behaviour was reported by parents and students alike. The study of $\mathrm{Ng}$ and Nicholas (2013) presents some findings that resonate with the above. At the end of the first year of a programme during which personal digital assistant devices were adopted, students' increase in negativity and game playing were reported. According to $\mathrm{Ng}$ and Nicholas, students became less excited about using technology, and they reported it did not make learning more interesting or fun. In addition, several students expressed a preference for using personal mobile devices primarily for entertainment. These results, according to the authors, indicated non-sustainability of the programme. However, as $\mathrm{Ng}$ and Nicholas highlight, the results are not completely straightforward, as some teachers also reported student engagement and enthusiasm while using mobile devices in the classroom. 
Baker, Bernard, and Dumez-Féroc (2012) examined the extent to which students engaged in collaborative learning and discussing certain topics on a learning platform. Engagement was evaluated by the level of argumentation. According to the authors, students' interactions on the platform were dominated by non-argumentative discussions, suggesting that students were not engaged in the activity.

Subject-specific knowledge and skills: Several of the reviewed studies concentrated on students' knowledge acquisition, content understanding, or skills related to a certain discipline or subject; these reported the influences of digital technology use on students' learning as positive. For example, Alvarez-Marinelli et al. (2016) found that students using computerassisted language learning curricula achieved a numerically higher level of oral English proficiency than students in a control group. Similar findings were reported by Liontou (2015), who showed that students' mean reading performance was notably higher in the post-test after participating in an online English language classroom. Similarly, Semeraro et al. (2017) reported that longitudinal use of a serious game evidently improved students' knowledge and skills of CPR. Bicer and Capraro (2017) reported that a mathematics programme had positive effects on students' learning, as their mathematics performance improved after a year of receiving the intervention. According to Harnisch, Comstock, and Bruce (2014), teachers working in a STEM programme valued the diverse use of digital technologies, which enhanced students' understanding of certain disciplines, such as biology and chemistry. Finally, Ale, Loh, and Chib (2017) reported positive learning outcomes in a study that used laptops and certain programmes to enhance student learning. Focusing on functional literacy (defined as a specific learning outcome, as in languages and mathematics) they found that the test group's functional literacy was shown to be better than that of the control group. 
Transversal skills: Transversal skills or competences are not particular to any academic discipline but are essential for learning, working, and living in general (UNESCO International Bureau of Education 2013). The term encompasses a variety of skills, but the focus here, as in the articles we reviewed, is on critical thinking, knowledge creation, communication, and digital skills. Adhikari, Mathrani, and Scogings (2016) noted that students perceived their digital skills as improving during the programme. However, the results also suggested that students whose information literacy skills were inadequate had difficulties to find and apply information and make use of it in their studying (see also Adhikari et al. 2017). Furthermore, Courtois et al. (2014) found that some students experienced technical issues with devices and difficulties mastering a tablet as a learning instrument and not as entertainment. According to the authors, students' sense of perceived behavioural control (i.e. their control beliefs about the device) needs to be supported, as it can have an influence on learners' attitudes towards activity and devices. In addition, they found that a positive attitude resulted in a stronger sense of perceived behavioural control. Ale, Loh, and Chib (2017) also observed a significant increase in technological literacy within the test group. Their results showed that technological knowledge was positively associated with functional literacy (defined as a specific learning outcome). Paralleling the above studies of transversal skills learning, Ale, Loh, and Chib (2017) found that computer self-efficacy mediated the relationship between technological literacy and functional literacy.

In a different kind of study, Baker, Bernard, and Dumez-Féroc (2012) shifted the focus to investigate student discussions on an online platform. The aim was to support students' participation in collaborative argument and debate on the environment, in turn supporting learning. Using digital technologies, students could enhance their transversal skills, such as 
critical thinking, knowledge creation, and communication skills. The results indicated that, in general, students' interactions were dominated by non-argumentative themes, including informal chats and exchanges of opinion, although some students did not participate in the discussions. One interesting finding was that, in contrast to the small-group debates, less offtask discussion occurred in teacher-moderated debates. Wales's (2012) study about digital storytelling reported improvement in students' aesthetic skills and their confidence and ability with the technology during the project.

Learning experience: Some articles also approached digital learning by exploring students' learning experiences or by defining learning as studying. In some such cases, digital technology usage was found to have positive influences on student learning. For example, in Adhikari, Mathrani, and Scogings (2016), students' survey responses showed a marked increase in their perceived level of digital skills, and several students reported being more productive and feeling that the technology allowed them to collaborate more easily with others. Students also felt that the use of digital devices enhanced their ability to engage in critical analysis. Liontou (2015) also reported positive experiences of digital learning among students, with a majority of participants favouring online rather than traditional classes. Bate, MacNish, and Males (2012) compared students' and their parents' perceptions of the level of change in students' learning during the laptop programme. According to the authors, students perceived a higher level of change than their parents did.

Negative indications on learning were also discovered. $\mathrm{Ng}$ and Nicholas (2013) investigated students' beliefs towards using personal mobile devices in learning and found that, after one year of using the devices, there was a significant drop in students' beliefs that they would have learned better with technology. Students stated that the use of technology did not help them 
learn better or did not make learning easier. Adhikari, Mathrani, and Scogings (2016) also found that a small number of students participating in digital learning activities felt concern towards digital learning policy and the teaching and learning methods used. These students felt they could not learn and study in the way required, and, because of using the devices, they failed to develop handwriting skills and experienced physical issues, such as headaches. In addition, 'a significant proportion of students struggled to find, process, and apply information into their learning activities' (Adhikari, Mathrani, and Scogings 2016, 335).

Elements of the learning environment: Some of the studies that we reviewed examined how the elements of a learning environment, including both material and social resources, can influence students' digital learning. For example, Harnisch, Comstock, and Bruce (2014) found that, during the study programme, the emphasis in the classrooms shifted from using a certain technology to specific ways of working, such as critical and engaged inquiry. The authors concluded that meaningful technology integration depends on identifying the elements of a learning culture that can enhance the learner's creativity. Courtois et al. (2014), in turn, investigated the influence of subjective norms on actual use and intention to use digital technologies for learning, defined as 'the extent to which socially relevant actors approve or disapprove embracing the innovation in question' (Courtois et al. 2014, 279). Among their findings, they noted that previous positive attitude increased later susceptibility to a subjective norm. Focusing on material resources in the learning environment, Adhikari, Mathrani, and Scogings (2016) found that some students had limited access to digital technologies, especially in informal learning settings. In addition, there were some issues of compatibility between different digital devices, which disturbed teaching and learning, and could cause a digital divide and hamper digital learning. 
Identity: One article (Wales 2012) discussed digital technologies' ability to support students' identity development. According to Wales, digital storytelling projects provided an environment for students to practise and present different possible sides of themselves, and to create possible futures and expressions of opinion.

\section{Discussion and conclusions}

In the present study, we explored recent longitudinal studies on digital learning. By focusing on the 13 studies, our aim was to highlight central features of the evidence base in this fastmoving area of research. We first explored in general the kinds of study published on the topic. It became clear that studies defined as 'longitudinal' approached digital learning in various ways—-differing, for example, in terms of research design and methods, duration, number of respondents, and digital technologies used. By categorizing the studies in terms of their orientation to learning, our aim was to assemble essential insights concerning the influences of digital technology usage on student learning. In all, we identified six aspects of learning on which the studies focused: affection, attitude, and motivation; subject-specific knowledge and skills; transversal skills; learning experience; elements of the learning environment; and identity.

Based on this exploration, no straightforward conclusions about the influences of digital technology use on students' learning can be made: it is not possible to confirm clearly that student learning benefits from the use of digital technologies over extended periods of time. Some studies (e.g. Ale, Loh, and Chib 2017; Liontou 2015) suggest that digital technologies 
can enhance learning and motivate students, but the considerable variation in study designs and aims make it impossible and inappropriate to generalise. Kozma (2010) noted the difficulty of identifying and measuring the real impact of digital technology usage on learning. As Stevenson $(2013,148)$ stated, '[w]hether and to what extent digital technologies actually have impacts on school pupils' learning are questions which do not have clear answers.' In his view, it can be hard to decide which factors should be considered as influences and how these are to be measured in a given educational context.

As learning is a complex phenomenon and, therefore, difficult to define comprehensively, it is crucial to understand its many dimensions when integrating digital technologies into teaching practice and curricula. It is also important to be aware that digital technologies may have unintended or unwanted effects on learning. For example, some of the studies we reviewed (e.g. Bate, MacNish, and Males 2012) described students' off-topic use of digital technologies during the study project. Although this may have negative influences on student learning in relation to certain study objectives, it can also be viewed from the perspective of learning transversal skills (e.g. European Commission 2018a). This raises a number of questions-for example, to what extent do children learn technological skills when using technologies for noneducational purposes? how can these skills support educational objectives? and, what kinds of activity would ultimately best promote study objectives and in what timeframe? To address to these questions, more diverse longitudinal research is needed.

In conclusion, this study offers insight into the current state of longitudinal research on digital learning in the context of primary and secondary education. It captures the variety of earlier studies on digital learning and reviews the reported influences of longitudinal digital technology 
use on students' learning. Rather than providing a comprehensive picture, this study presents a multi-dimensional picture of current research and its many aspects.

\section{Limitations}

As only two databases were used to identify papers, it is important to recognize that some key studies may not have been included. In addition, the study is limited in scope, as it focuses on only a very small selection of the literature. Based on our inclusion and exclusion criteria, we identified a small collection of 13 studies for the final analysis. This may in part be due to the focus of the study and the choice of criteria; as we concentrated on studies that described themselves as 'longitudinal': some papers may have been excluded even though they used a similar research design and methods to the ones included to the analysis. On the other hand, the low number of studies included in exploration may also indicate the strong need for further longitudinal research on the topic. We did not define 'longitudinal study' precisely or in advance; instead, we wanted to explore studies that described their orientation in that way. In so doing, we acknowledge that 'longitudinal' has different meanings in a research context, and some of the reviewed studies may be considered more longitudinal in design than others, depending on definitions used. This in itself made it more difficult to compare the various studies. It is also important to note that for present purposes, we did not further assess the quality characteristics of the reviewed studies (other than through our focus on peer review literature); nor did we evaluate the various ways in which they approached learning or executed longitudinal research.

Finally, the studies we reviewed were conducted in various countries and continents that differ, for example, in cultural and economic as well as educational terms. Studies and their findings 
are always linked to a certain cultural context: this must be acknowledged when interpreting the results.

\section{Suggestions for further research}

Future studies could usefully explore specific types of longitudinal research on digital learning that share the same study design or method. For more detailed consideration of the influences of technology use on learning, we suggest that future literature reviews could investigate specific orientations, methods, or research designs in the interests of meaningful comparison.

The present study explored the influences of digital technology usage on student learning as approached by the selected studies. We have concentrated on the different themes and categories that emerged from our qualitative content analysis, and further thematic analysis is needed for a more detailed picture. In addition, the focus could usefully be expanded to early childhood and higher and adult education contexts that were excluded here.

\section{Funding}

This work was supported by the Ministry of Education and Culture in Finland under Grant OKM/172/523/2016.

\section{Declaration of interest statement}

No potential conflict of interests.

\section{Acknowledgements}

The authors wish to thank the Ministry of Education and Culture in Finland for funding the TOTEEMI project, of which this study is a part. 


\section{References}

Adhikari, J., A. Mathrani, and C. Scogings. 2016. "Bring Your Own Devices Classroom: Exploring the Issue of Digital Divide in the Teaching and Learning Contexts." Interactive Technology and Smart Education 13 (4): 323-343.

Adhikari, J., C. Scogings, A. Mathrani, and I. Sofat. 2017. "Evolving Digital Divides in Information Literacy and Learning Outcomes: A BYOD journey in a Secondary School". The International Journal of Information and Learning Technology 34 (4): 290-306.

Ale, K., Y. A.-C. Loh, and A. Chib. 2017. "Contextualized-OLPC Education Project in Rural India: Measuring Learning Impact and Mediation of Computer Self-Efficacy.” Educational Technology Research and Development 65: 769-794.

Alvarez-Marinelli, H., M. Blanco, R. Lara-Alecio, B. J. Irby, F. Tong, K. Stanley, and Y. Fan. 2016. "Computer Assisted English Language Learning in Costa Rican Elementary Schools: An Experimental Study.” Computer Assisted Language Learning 29 (1): 103-126.

Ananiadou, K., and M. Claro. 2009. 21 st Century Skills and Competences for New Millennium Learners in OECD Countries. OECD Education Working Paper No. 41. Paris: OECD Publishing.

Baker, M., F.-X. Bernard, and I. Dumez-Féroc. 2012. "Integrating Computer-Supported Collaborative Learning into the Classroom: The Anatomy of a Failure." Journal of Computer Assisted Learning 28: 161-176. 
Bate, F., J. MacNish, and S. Males. 2012. "Understanding Parent Perceptions of a 1:1 Laptop Program in Western Australia.” Australian Educational Computing 27 (2): 18-21.

Bicer, A., and R. M. Capraro. 2017. "Longitudinal Effects of Technology Integration and Teacher Professional Development on Students' Mathematics Achievement." EURASIA Journal of Mathematics Science and Technology Education 13 (3): 815-833.

Binkley, M., O. Erstad, J. Herman, S. Raizen, M. Ripley, M. Miller-Ricci, and M. Rumble. 2012. "Defining Twenty-First Century Skills." In Assessment and Teaching of 21st Century Skills, edited by P. Griffin, B. McGaw, and E. Care, 17-66. Dordrecht: Springer.

Blau, I. and T. Shamir-Inbal. 2017. "Digital Competences and Long-Term ICT Integration in School Culture: The Perspective of Elementary School Leaders." Education and Information Technologies 22 (3): 769-787.

Bray, A., and B. Tangney. 2017. "Technology Usage in Mathematics Education Research: A Systematic Review of Recent Trends." Computers and Education 114: 255-273.

Chadegani, A. A., H. Salehi, M. Yunus, H. Farhadi, M. Fooladi, M. Farhadi, and N. Ale Ebrahim. 2013. “A Comparison Between Two Main Academic Literature Collections: Web of Science and Scopus Databases.” Asian Social Science 9 (5): 18-26. https://ssrn.com/abstract $=2257540$ 
Courtois, C., H. Montrieux, F. De Grove, A. Raes, L. De Marez, and T. Schellens. 2014.

"Student Acceptance of Tablet Devices in Secondary Education: A Three-Wave Longitudinal Cross-Lagged Case Study." Computers in Human Behavior 35: 278-286.

De Houwer, J., D. Barnes-Holmes, and A. Moors. 2013. "What is Learning? On the Nature and Merits of a Functional Definition of Learning." Psychonomic Bulletin \& Review 20 (4): 631642.

Dunlosky, J., K. A. Rawson, E. J. Marsh, M. J. Nathan, and D. T. Willingham. 2013. “Improving Students' Learning with Effective Learning Techniques: Promising Directions from Cognitive and Educational Psychology." Psychological Science in the Public Interest 14 (1): 4-58.

Eshghinejad, S. 2016. “EFL Students' Attitudes Toward Learning English Language: The Case Study of Kashan University Students.” Cogent Education 3 (1): 1-13.

European Commission. 2018a. Proposal for a Council Recommendation of Key Competences for Lifelong Learning. Brussels.

European Commission. 2018b. Proposal for a Council Recommendation on Promoting Common Values, Inclusive Education, and the European Dimension of Teaching. Brussels.

Geith, C., and K. Vignare. 2008. "Access to Education with Online Learning and Open Educational Resources: Can They Close the Gap?" Journal of Asynchronous Learning Networks 12 (1): 105-126. 
Groff, J. 2013. Technology-Rich Innovative Learning Environments. OECD Working Paper. http://www.oecd.org/education/ceri/Technology-

Rich\%20Innovative\%20Learning\%20Environments\%20by\%20Jennifer\%20Groff.pdf

Harnisch, D. L., S. L. Comstock, and B. C. Bruce. 2014. "Collaborative Inquiry with Technology in Secondary Science Classrooms: Professional Learning Community Development at Work.” E-Learning and Digital Media 11 (5): 495-505.

Hergenhahn, B. R., and M. H. Olson. 2005. An Introduction to Theories of Learning. 7th ed. Upper Saddle River, NJ: Pearson/Prentice Hall.

Higgins, S., Z. Xiao, and M. Katsipataki. 2012. The Impact of Digital Technology on Learning: A Summary for the Education Endowment Foundation. Full Report. https://v1.educationendowmentfoundation.org.uk/uploads/pdf/The_Impact_of_Digital_Techn ology_on_Learning_-_Executive_Summary_(2012).pdf

Kangas, M., A. Koskinen, and L. Krokfors. 2017. "A Qualitative Literature Review of Educational Games in the Classroom: The Teacher's Pedagogical Activities." Teachers and Teaching 23 (4): 451-470.

Ketonen, E. E., A. Haarala-Muhonen, L. Hirsto, J. J. Hänninen, K. Wähälä, and K. Lonka. 2016. "Am I in the Right Place? Academic Engagement and Study Success During the First Years at University." Learning and Individual Differences 51: 141-148. 
Kozma, R. B. 2010. “The Technological, Economic, and Social Contexts for Educational ICT Policy." In Transforming Education: The Power of ICT Policies. Paris: United Nations Educational, Scientific and Cultural Organization.

Liontou, T. 2015. 'Intermediate Greek EFL Learners' Attitudes to On-Line Teaching Practices: A Blended Task-Based English Language Learning Approach." Teaching English with Technology 15 (2): 81-93.

Lonka, K., L. Hietajärvi, M. Moisala, H. Tuominen-Soini, L. J. Vaara, K. Hakkarainen, and K. Salmela-Aro. 2015. "Working Document I." In Innovative Schools: Teaching \& Learning in the Digital Era-Workshop Documentation, 5-46. Brussels: European Parliament.

Menard, S. W. 1991. Longitudinal Research. Newbury Park, CA: SAGE Publications.

Mikropoulos, T. A., and A. Natsis. 2011. "Educational Virtual Environments: A Ten-Year Review of Empirical Research (1999-2009)." Computers and Education 56 (3): 769-780.

Nagy, P., and B. Koles. 2014. "The Digital Transformation of Human Identity: Towards a Conceptual Model of Virtual Identity in Virtual Worlds." Convergence: The International Journal of Research into New Media Technologies 20 (3): 276-292.

Ng, W., and H. Nicholas. 2013. "A Framework for Sustainable Mobile Learning in Schools.” British Journal of Educational Technology 44 (5): 695-715. 
Olofsson, A. D., J. O. Lindberg, G. Fransson, and T. E. Hauge. 2011. "Uptake and Use of Digital Technologies in Primary and Secondary Schools—A Thematic Review of Research." Nordic Journal of Digital Literacy 6 (4): 207-225.

Pérez-Sanagustín, M., M. Nussbaum, I. Hilliger C. Alario-Hoyos, R. S. Heller, P. Twining, and C. C. Tsai. 2017. "Research on ICT in K-12 Schools: A Review of Experimental and SurveyBased Studies in Computers \& Education 2011 to 2015." Computers and Education 104: A1A15.

Pyyry, N., L. Tainio, K. Juuti, R. Vasquez, and M. Paananen. 2017. “Foreword.” In Changing Subjects, Changing Pedagogies: Diversities in School and Education, edited by N. Pyyry, L. Tainio, K. Juuti, R. Vasquez, and M. Paananen, 13. Helsinki: Publications of the Finnish Research Association for Subject Didactics, Studies in Subject Didactics.

Rautopuro, J. and E. Harjunen. 2017. “Mode Effect in Large-Scale Assessment.” In Changing Subjects, Changing Pedagogies: Diversities in School and Education, edited by N. Pyyry, L. Tainio, K. Juuti, R. Vasquez, and M. Paananen, 260-274. Helsinki: Publications of the Finnish Research Association for Subject Didactics, Studies in Subject Didactics.

Semeraro, F., A. Frisoli, C. Loconsole, N. Mastronicola, F. Stroppa, G. Ristagno, A. Scapigliati, L. Marchetti, and E. Cerchiari. 2017. "Kids (Learn How to) Save Lives in the School with the Serious Game Relive.” Resuscitation 116: 27-32. 
Stahl, G. 2013. "Theories of Cognition in Collaborative Learning." In The International Handbook of Collaborative Learning, edited by C. E. Hmelo-Silver, C. A. Chinn, C. K. K. Chan, and A. O’Donnell, 74-90. New York, NY: Routledge.

Stevenson, I. 2013. "Does Technology Have an Impact on Learning? A Fuzzy Set Analysis of Historical Data on the Role of Digital Repertoires in Shaping the Outcomes of Classroom Pedagogy." Computers and Education 69: 148-158.

Tay, H. Y. 2016. "Longitudinal Study on Impact of iPad use on Teaching and Learning." Cogent Education 3: 1-22.

Tilson, D., K. Lyytinen, and C. Sørensen. 2010. "Research Commentary: Digital Infrastructures: The Missing IS Research Agenda.” Information Systems Research 21 (4): 748759.

Tyng, C. M., H. U. Amin, M. N. M. Saad, and A. S. Malik. 2017. "The Influences of Emotion on Learning and Memory." Frontiers in Psychology 8: 1-22.

UNESCO International Bureau of Education. 2013. IBE Glossary of Curriculum Terminology. http://www.ibe.unesco.org/fileadmin/user_upload/Publications/IBE_GlossaryCurriculumTer minoloG12013_eng.pdf

Vygotsky, L. S. 1978. Mind in Society: The Development of Higher Psychological Processes, edited by M. Cole, V. John-Steiner, S. Scribner, and E. Souberman. Cambridge, MA: The MIT Press. 
Wales, P. 2012. “Telling Tales in and out of School: Youth Performativities with Digital Storytelling." Research in Drama Education: The Journal of Applied Theatre and Performance 17 (4): 535-552.

Yuan, L. and S. Powell. 2013. "MOOCs and Disruptive Innovation: Implications for Higher Education." eLearning Papers 33.

https://www.openeducationeuropa.eu/sites/default/files/legacy_files/asset/Indepth_33_2_0.pdf 
Figure 1. Article selection process.

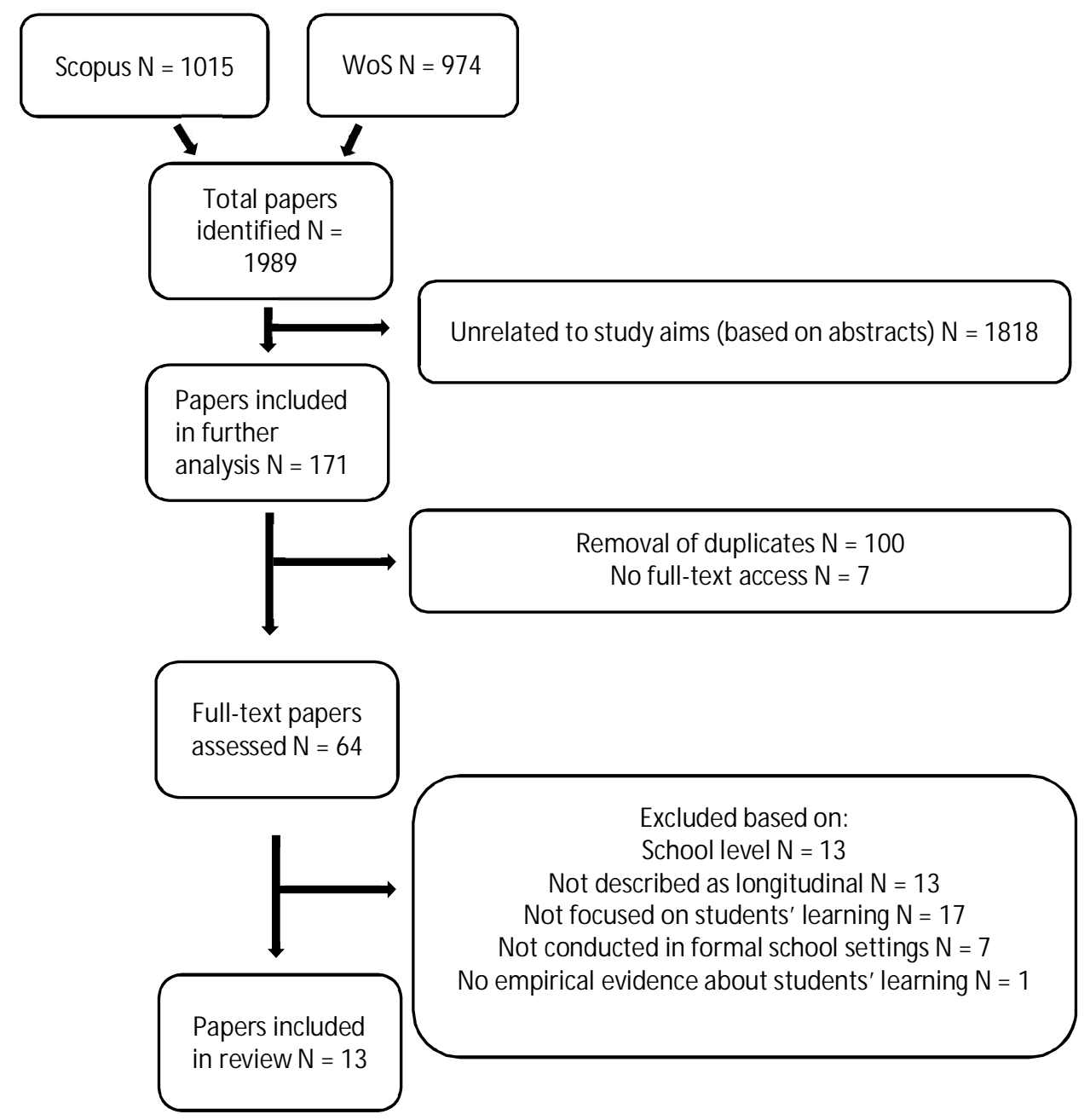


Table 1. Summarised description of the reviewed articles.

\begin{tabular}{|c|c|c|c|c|c|c|c|c|}
\hline Author(s) & Research design & $\begin{array}{l}\text { Data collection / } \\
\text { Methods }\end{array}$ & $\begin{array}{l}\text { Duration } \\
\text { (ca.) }\end{array}$ & Participants & Digital technology & $\begin{array}{l}\text { School subject (in } \\
\text { which the technology } \\
\text { was integrated) }\end{array}$ & $\begin{array}{l}\text { Educational } \\
\text { context }\end{array}$ & Location \\
\hline $\begin{array}{l}\text { Adhikari, M athrani, and } \\
\text { Scogings (2016). }\end{array}$ & Case study & $\begin{array}{l}\text { Interviews } \\
\text { Online surveys } \\
\text { Observations }\end{array}$ & 3 years & $\begin{array}{l}\text { Surveys: } 63 \text { teachers, } 71 \\
\text { parents, and } 98 \text { students } \\
\text { Interviews: } 9 \text { teachers, } 7 \\
\text { parents, and } 10 \text { students }\end{array}$ & Personal device & M ultiple subjects & $\begin{array}{l}\text { Secondary } \\
\text { school }\end{array}$ & New Zealand \\
\hline Adhikari et al. (2017) & Descriptive design & Interviews & 5 years & 5 teachers & Personal device & M ultiple subjects & $\begin{array}{l}\text { Secondary } \\
\text { school }\end{array}$ & New Zealand \\
\hline $\begin{array}{l}\text { Ale, Loh, and Chib } \\
\text { (2017) }\end{array}$ & $\begin{array}{l}\text { Experimental or } \\
\text { quasi-experimental } \\
\text { design }\end{array}$ & $\begin{array}{l}\text { Pre- and post- } \\
\text { experiment measures } \\
\text { with test and control } \\
\text { groups }\end{array}$ & 5 months & 205 students & $\begin{array}{l}\text { Computer } \\
\text { program or } \\
\text { software }\end{array}$ & $\begin{array}{l}\text { M athematics } \\
\text { English language } \\
\text { Hindi language }\end{array}$ & $\begin{array}{l}\text { Primary } \\
\text { school }\end{array}$ & India \\
\hline $\begin{array}{l}\text { Alvarez-M arinelli et al. } \\
(2016)\end{array}$ & $\begin{array}{l}\text { Experimental or } \\
\text { quasi-experimental } \\
\text { design }\end{array}$ & $\begin{array}{l}\text { Pre- and post-tests with } \\
\text { test and control groups }\end{array}$ & 1 year & 816 students & $\begin{array}{l}\text { Computer } \\
\text { program or } \\
\text { software }\end{array}$ & English language & $\begin{array}{l}\text { Primary } \\
\text { school }\end{array}$ & Costa Rica \\
\hline $\begin{array}{l}\text { Baker, Bernard, and } \\
\text { Dumez-Féroc (2012) }\end{array}$ & Case study & $\begin{array}{l}\text { Trace logs of chat } \\
\text { interactions } \\
\text { Products of the project } \\
\text { Observations } \\
\text { Discussions with the } \\
\text { teacher }\end{array}$ & 6 months & 1 teacher, 24 students & $\begin{array}{l}\text { Computer } \\
\text { program or } \\
\text { software }\end{array}$ & History-geography & $\begin{array}{l}\text { Secondary } \\
\text { school }\end{array}$ & France \\
\hline $\begin{array}{l}\text { Bate, MacNish, and } \\
\text { Males (2012) }\end{array}$ & Case study & $\begin{array}{l}\text { Questionnaires } \\
\text { Interviews } \\
\text { Focus groups } \\
\text { Observations }\end{array}$ & 3 years & $\begin{array}{l}196 \text { students, } 60 \\
\text { teachers, and } 196 \text { parents }\end{array}$ & Personal device & Multiple subjects & $\begin{array}{l}\text { Primary } \\
\text { school } \\
\text { Secondary } \\
\text { school }\end{array}$ & Australia \\
\hline $\begin{array}{l}\text { Bicer and Capraro } \\
\text { (2017) }\end{array}$ & $\begin{array}{l}\text { Experimental or } \\
\text { quasi-experimental } \\
\text { design }\end{array}$ & $\begin{array}{l}\text { Mathematics scores of a } \\
\text { statewide standardized } \\
\text { tests with test and } \\
\text { control groups }\end{array}$ & 1 year & 1263 students & $\begin{array}{l}\text { Computer } \\
\text { program or } \\
\text { software }\end{array}$ & M athematics & $\begin{array}{l}\text { Secondary } \\
\text { school }\end{array}$ & United States \\
\hline Courtois et al. (2014) & Descriptive design & Online questionnaires & 7 months & 678 students & Personal device & M ultiple subjects & $\begin{array}{l}\text { Secondary } \\
\text { school }\end{array}$ & Belgium (Flanders) \\
\hline $\begin{array}{l}\text { Harnisch, Comstock, } \\
\text { and Bruce (2014) }\end{array}$ & Case study & $\begin{array}{l}\text { Interviews } \\
\text { Online surveys } \\
\text { Observations } \\
\text { Photography } \\
\text { Video } \\
\text { Products of the projects } \\
\text { Personal reflections }\end{array}$ & 8 years & $\begin{array}{l}\text { Teachers, graduate } \\
\text { students, and students } \\
\text { (Exact number of } \\
\text { participants } n / a \text { ) }\end{array}$ & $\begin{array}{l}\text { Computer } \\
\text { program or } \\
\text { software }\end{array}$ & M ultiple subjects & $\begin{array}{l}\text { Secondary } \\
\text { school }\end{array}$ & United States \\
\hline
\end{tabular}

Restricted Page 1 of 2 


\begin{tabular}{|c|c|c|c|c|c|c|c|c|}
\hline Liontou (2015) & $\begin{array}{l}\text { Experimental or } \\
\text { quasi-experimental } \\
\text { design }\end{array}$ & $\begin{array}{l}\text { Questionnaire } \\
\text { Pre- and post-tests } \\
\text { without control group }\end{array}$ & 1 year & 40 students & $\begin{array}{l}\text { Online learning } \\
\text { environment }\end{array}$ & English language & $\begin{array}{l}\text { Secondary } \\
\text { school }\end{array}$ & Greece \\
\hline $\mathrm{Ng}$ and Nicholas (2013) & Case study & $\begin{array}{l}\text { Pre- and post- } \\
\text { questionnaires } \\
\text { Observations } \\
\text { Interviews } \\
\text { Reflective journal }\end{array}$ & 3 years & $\begin{array}{l}57 \text { students, } 25 \text { teachers, } \\
1 \text { principal, and } 1 \text { program } \\
\text { coordinator }\end{array}$ & Personal device & M ultiple subjects & $\begin{array}{l}\text { Secondary } \\
\text { school }\end{array}$ & Australia \\
\hline Semeraro et al. (2017) & $\begin{array}{l}\text { Experimental or } \\
\text { quasi-experimental } \\
\text { design }\end{array}$ & $\begin{array}{l}\text { Pre- and post-tests } \\
\text { without control group } \\
\text { Questionnaires }\end{array}$ & 8 months & 65 students & $\begin{array}{l}\text { Computer } \\
\text { program or } \\
\text { software }\end{array}$ & Not specified & $\begin{array}{l}\text { Secondary } \\
\text { school }\end{array}$ & Italy \\
\hline Wales (2012) & Case study & $\begin{array}{l}\text { Interviews } \\
\text { Video } \\
\text { Observations } \\
\text { Digital stories and other } \\
\text { products of the projects }\end{array}$ & $\begin{array}{l}\text { From } 10 \\
\text { months to } \\
3.5 \text { years }\end{array}$ & 3 students & Method & Not specified & $\begin{array}{l}\text { Secondary } \\
\text { school }\end{array}$ & Singapore \\
\hline
\end{tabular}

